\title{
Lessons Learnt from Bridge Collapse: A View of Sustainable Management
}

\author{
Ji-Shuang Tan ${ }^{1}$, Khalid Elbaz ${ }^{2,3, * \mathbb{C}}$, Zhi-Feng Wang ${ }^{4}$, Jack Shui Shen ${ }^{1, * \mathbb{C}}$ and Jun Chen ${ }^{1}$ \\ 1 Department of Civil Engineering, School of Naval Architecture, Ocean, and Civil Engineering, Shanghai Jiao \\ Tong University, Shanghai 200240, China; tanjishuang@sjtu.edu.cn (J.-S.T.); chen_jun@sjtu.edu.cn (J.C.) \\ 2 Key Laboratory of Intelligent Manufacturing Technology (Shantou University), Ministry of Education, \\ Shantou 515063, China \\ 3 Department of Civil and Environmental Engineering, College of Engineering, Shantou University, \\ Shantou 515063, China \\ 4 School of Highway, Chang'an University, Xi'an 710064, China; zhifeng.wang@chd.edu.cn \\ * Correspondence: khalid@stu.edu.cn (K.E.); slshen@sjtu.edu.cn (J.S.S.)
}

Received: 14 January 2020; Accepted: 4 February 2020; Published: 7 February 2020

\begin{abstract}
Bridge failure is one of the worst infrastructural disasters. This paper investigates the risk of bridge infrastructures in the view of sustainable management. Statistics on bridge failures from 2009 to 2019 in China show that most of these failures are related to anthropic factors. The collapse of the Zijin Bridge on 14 June 2019 in Heyuan City of Guangdong Province, China is used as a case to perform detailed analysis. Superficially, bridge collapse is a technical problem rather than a management problem. However, the deep reason for this kind of bridge failure may be due to the lack of sustainable management. In order to verify this point of view, both fault tree analysis (FTA) and strategic environmental assessment (SEA) for the bridge failure and later impact on society are conducted. According to the FTA results, the failure of the arch foot is the direct trigger of the Zijin Bridge collapse. Since a lack of real-time monitoring, risk assessment and other management issues are potential factors causing bridge collapse, strategic environmental assessment (SEA) is used to investigate the management issues related to the economy, culture, human health and environmental sustainability in more depth. The low total SEA result shows poor project management and a high safety risk. Finally, the specific managerial measures are proposed to improve the sustainability of infrastructures.
\end{abstract}

Keywords: bridge failures; fault tree analysis (FTA); strategic environmental assessment (SEA); sustainability

\section{Introduction}

Economic boom has sped up urbanization over the past four decades in China. Urbanization leads to a continuous increase in demand for urban infrastructures, including bridges, highways, water supply and sewage systems, electric and electronic pipelines and metro systems [1-8]. However, the service life of these infrastructural facilities often falls short of the designed life due to natural phenomena (e.g., earthquakes, floods, typhoons, ground subsidence) and lack of proper expertise and sustainable concept of the management layer [9-16]. Some facilities collapsed during the construction period, while others failed during their service life [17-25], which had harmful impacts on the social community and environment $[26,27]$. Bridge failures are one of the most severe infrastructure problems facing the world today [28] and usually cause significant economic losses and casualties. This has elicited a considerable amount of attention from designers, engineers, researchers, and policy makers [29-31]. Bridge failures pose an imminent threat to life and property during their service life, 
which reinforces the need to implement updated sustainability assessments and optimal risk mitigation procedures [32,33].

One aspect of studying engineering failures is the relationship between the failure and the growth of engineering knowledge, which ensures the sustainable development of society [12,34]. The engineering profession must extract as much information as possible from these failures. The lessons from these bridge failures should be thoroughly studied to ensure the future safety, durability and construction cost of bridges [35]. In response to a large number of bridge failures, researchers [36-39] have focused on three aspects of bridge failure: (i) the general situation and development trend of bridge failures; (ii) bridge safety evaluation based on structural monitoring and mechanism analysis, and (iii) risk assessment and control for sustainability and environment health. The general situation of bridge failures is illustrated by failure data involving location, occurrence time, life and economic loss $[31,37,38]$. However, the likelihood and degree of uncertainty when a mysterious event leads to system failure is difficult to directly measure by experts [36,39]. Therefore, it is necessary to focus on facilitating bridge failure risk assessment and establishing a sound bridge management system.

The existing bridge management system (BMS) includes several methods $[38,40]$ : (i) the grey system theory and Bayesian networks; (ii) analytic hierarchy process (AHP) and fuzzy comprehensive evaluation (FCE); (iii) comprehensive evaluation based on onsite inspection. The grey system theory and Bayesian networks are used to predict bridge technical conditions [41]. AHP-FCE is used to assess the risk of the bridge damage degree or its bearing capacity [4]. The current bridge management regulations in China are mainly used in comprehensive evaluation based on onsite inspection [42-55]. Recently, fault tree analysis (FTA) and strategic environmental assessment (SEA) modern practices have been expanded in project management for sustainability [56,57]. Fault tree analysis (FTA) and strategic environmental assessment (SEA) are used to formulate the comprehensive management guidelines. FTA is a reasonable and appropriate approach for fault identification, which can help in the identification of failure paths [56]. SEA is an effective tool for integrating principles of society, economy and environment, which represents the three pillars of sustainability [34,51]. Markus and Emmelin [45] adopted a detailed description of the decision-making process based on Öresund Bridge using SEA, which demonstrated that the SEA is a good criteria for large-scale projects. Although extensive studies have been carried out on the methods of management systems, the risk assessment of bridge infrastructures is still of keen interest.

This paper focuses on bridge management in terms of sustainability, in which data analysis and a case study on the managerial reasons for bridge failure and multiple impacts are investigated in detail. In order to reveal the managerial reasons, a summary of bridge failures from 2009 to 2019 is presented. The objectives of this paper are: (i) to investigate the managerial reasons for bridge failure using FTA and the failure-induced environmental impact using SEA; (ii) to propose mitigation countermeasures for bridge failures in managerial aspects, and (iii) to provide a reference for governments to maintain sustainability and safety measures.

\section{Bridge Failures from 2009 to 2019}

To understand the background of the current situation of bridge failures, the data regarding various pieces of basic information in the field of bridges are selected and analyzed. Figure 1 summarizes the causes of the 418 reported bridge collapses during the period between 2009 and 2019 in China [46,47]. As shown in Figure 1a, the causes of bridge failures can be summarized into six types: construction, flooding, scouring, collision, overload, design defects and earthquake, and wind or fire. Construction $(28.7 \%)$, flooding or scouring $(21.3 \%)$, and collision (18.7\%) are the three main causes of bridge failure, which is in accordance with former research statistics [48]. In addition, overload (9.1\%) is one of the most important causes of bridge accidents, which is more serious than design defects $(8.6 \%)$. Accumulated damages by earthquake and other hazards impose negative effect on bridge structure [35] and lead to failures, accounting for $6.4 \%$. 


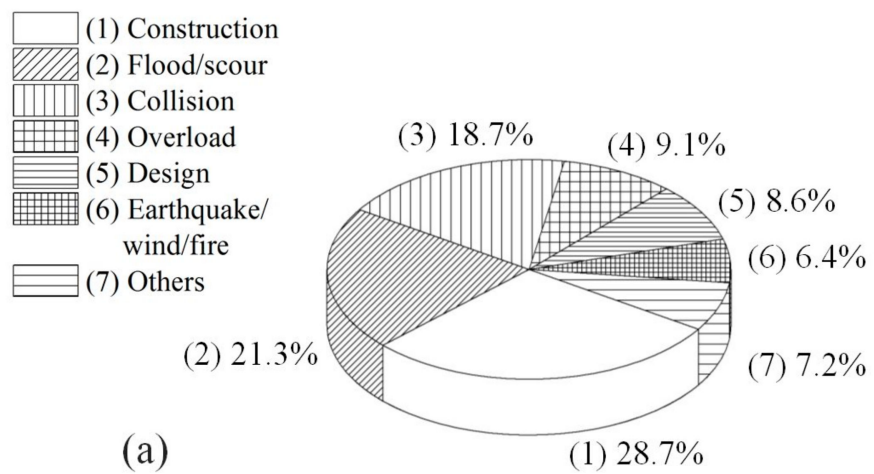

\section{Natural factors}

Anthropic factors

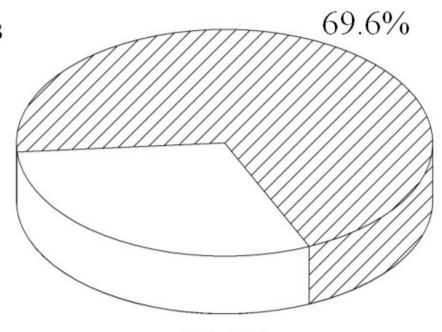

(b)

$30.4 \%$

Figure 1. The distribution of bridge failure causes between 2009 and 2018.: (a) percentage of collapse reasons and (b) proportion of natural factors and anthropic factors leading to bridge failures.

The above six types can be further summarized as two major categories: natural factors and anthropic factors (Figure 1b). The proportion of failures caused by anthropic factors $(69.6 \%)$ is much greater than that by natural factors (30.4\%). It can be concluded that the management issues related to construction, design, maintenance and supervision are the key causes of these bridge collapses. The related detailed causes could be discussed for the specific case of Zijing Bridge, the principal causes were in the following analysis.

Figure 2 illustrates the number of bridge collapses both in the service and in the construction stage. Meanwhile, the casualties from 2009 to 2018 are shown in the fold line. As shown in Figure 2, the number of bridge collapses and causalities increased annually. However, the peak values of collapses and associated casualties do not coincide. The high casualties in 2010, 2013 and 2018 were due to several high-casualty collapses. The number of casualties did not increase largely with the increase in collapses from 2014 to 2018, which can be ascribed to advancements of rescue and disaster warning and mitigation work and improvement of safety awareness. Moreover, compared with the failures during construction, more and more collapses occur in the service stage. It could be inferred that in recent years, the problem of vehicle overloading has become more and more serious with the development of the economy. Strong supervision and management are imminent for project construction.

Figure 3 summarizes the proportion of collapsed bridges with different service life. The life of most collapsed bridges falls in the age intervals of $0-10$ and 10-20 years, with the proportion of $30.3 \%$ and $33.8 \%$, respectively, while only $2.1 \%$ of collapsed bridges have a service life of more than 50 years. The low service life of bridges is a waste of social resources and harmful to the environment, which should be considered. In addition, the collapse percentage of bridge within 10-20 years of service life is the largest, rather than in the initial period of bridge service (0-10 years), which proves that the management problems in bridge service stage cannot be ignored. 


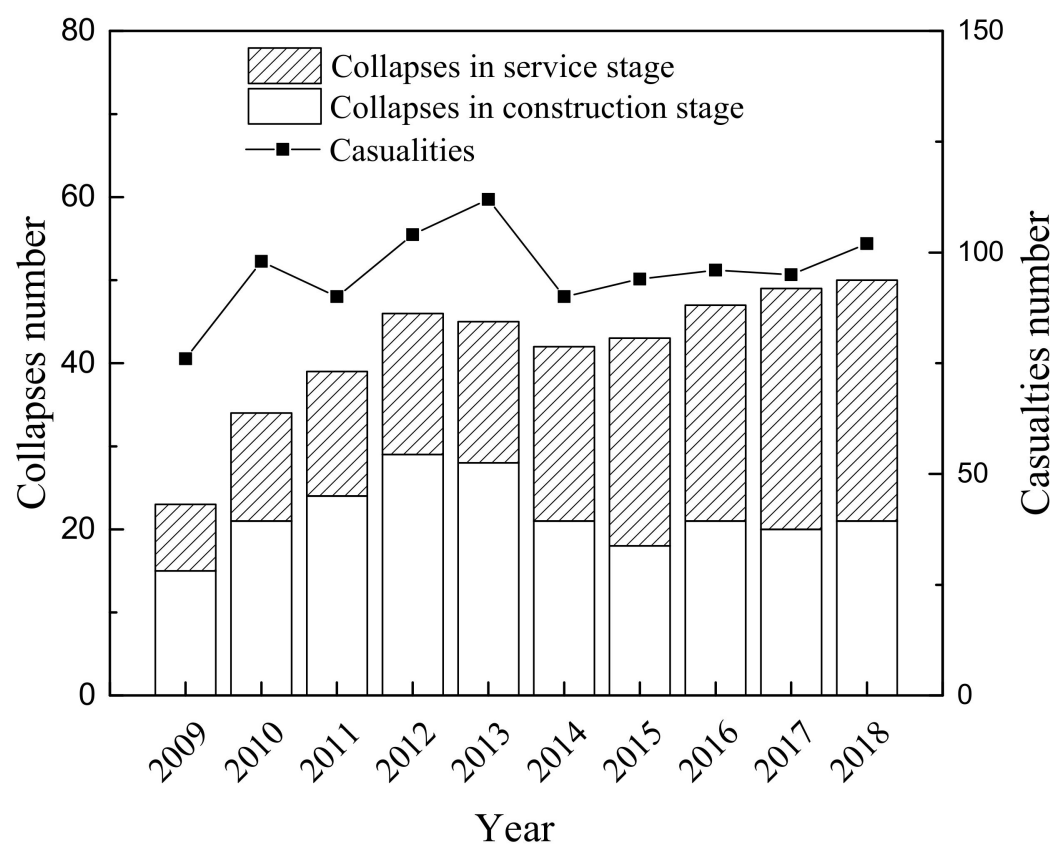

Figure 2. Number of bridge collapses and casualties between 2009 and 2018.

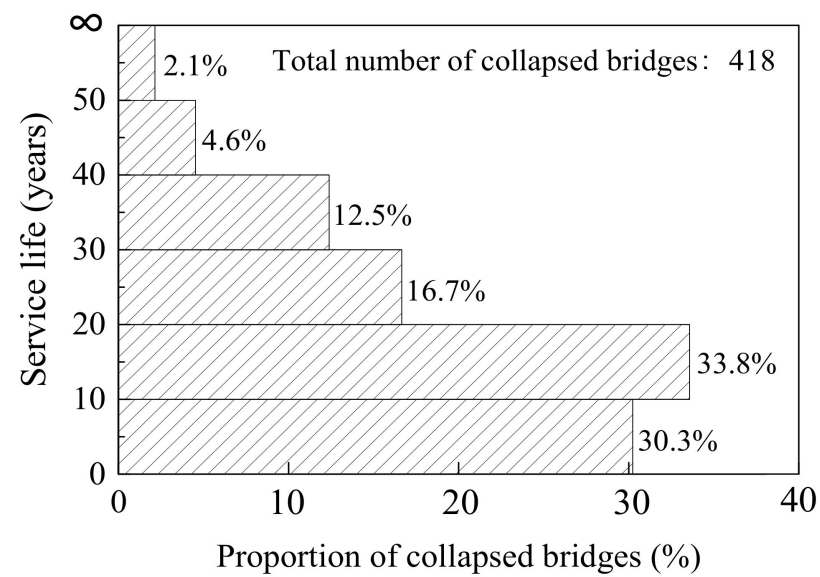

Figure 3. Life span distribution of bridges collapsed in the service stage between 2009 and 2018 .

\section{Case of Zijin Bridge}

Zijin Bridge was located on the outskirts of Heyuan City, Guangdong Province (see the map in Figure 4). Zijin Bridge was constructed and opened to traffic in 1972. It had been operational for 47 years before the collapse. This operational lifetime is significantly less than the designed lifespan of 100-120 years. The bridge spanned the Dongjiang River from northwest to southeast. It was a six-hole arch bridge, having a total length of $420.06 \mathrm{~m}$ and a width of $9 \mathrm{~m}$. It was the second river-crossing bridge constructed in Heyuan since 1949. The bridge was a symbol of Heyuan City.

In 2007, several small cracks appeared in an arch ring in the middle of Zijin Bridge, where a slight dislocation was observed in the west abutment. Management departments issued traffic restriction measures in 2008 to restrict the passage of medium-size and larger vehicles. The restriction was lifted in 2011 because of the inconvenience it caused to local transportation. Due to limitations of design regulations, the design load of the bridge at that time was low. As the traffic volume increased annually, damage to the asphalt pavement on the bridge deck occurred. Therefore, the bridge underwent significant maintenance in November 2015. Partial bridge deck girders were repaired, and slope-type protective fences were installed on both sides of the road. 

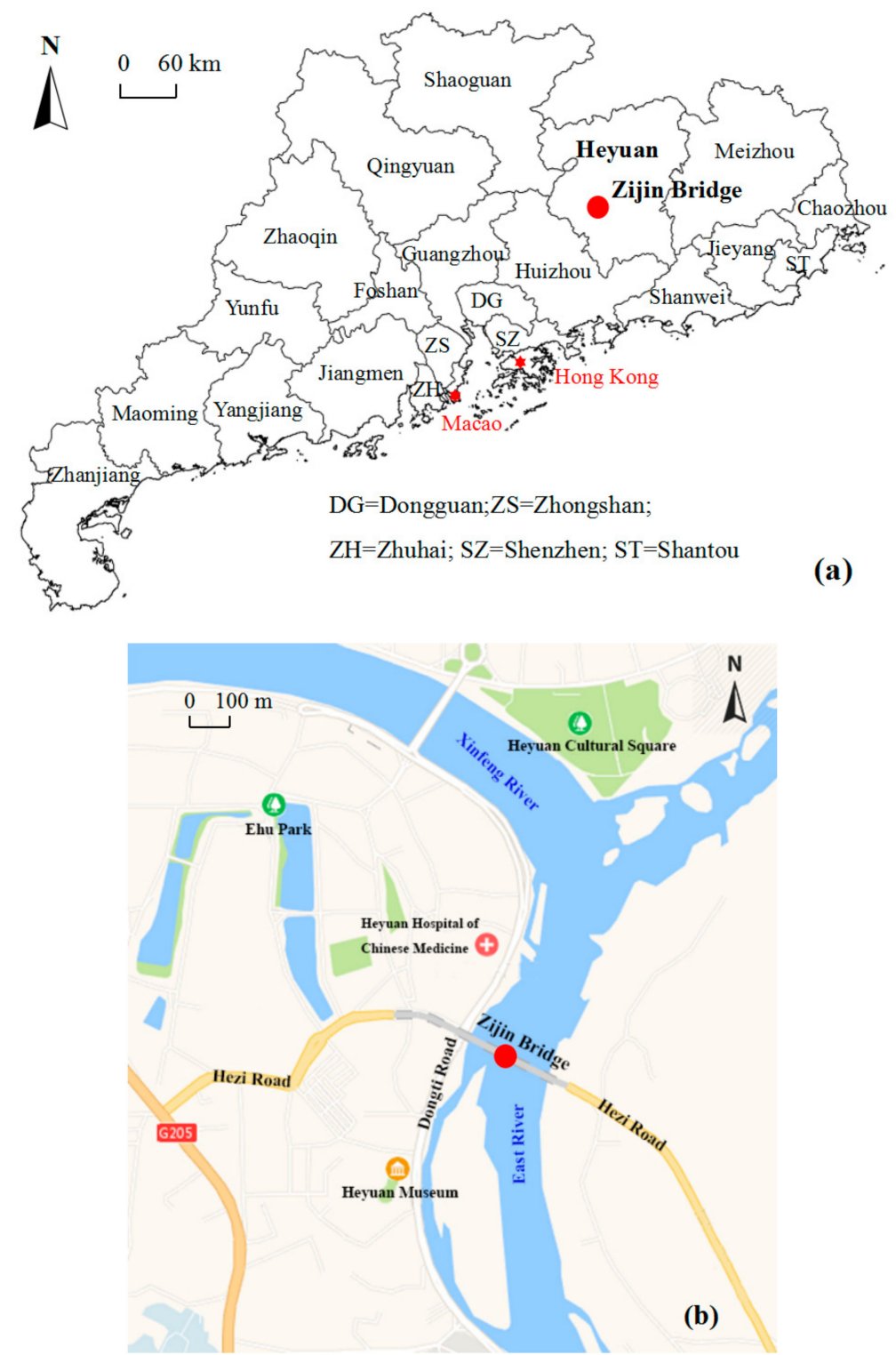

Figure 4. Location of Zijin Bridge: (a) in Guangdong Province and (b) surrounding area of the bridge.

The city of Heyuan was affected by heavy rain from May to June 2019 and suffered severe flooding at several locations. Fengshuba Reservoir in the upper reaches of the Zijin Bridge had discharged floodwater continuously for several days before the collapse happened. The water level of the Dongjiang River had also risen, and relatively turbulent flow occurred. According to the information provided by the local traffic bureau, the average daily traffic flow in the month before the collapse was approximately 7000 vehicles per day. At 2:12 a.m. on June 14, two sedan cars were driving sequentially over the bridge. When they reached the third and fourth spans, two spans of an arch collapsed one after the other, and then the middle pier column collapsed.

After that, Heyuan City Highway Bureau issued a bulletin on 17 July 2019 that the Zijin Bridge was in a highly dangerous and uncontrollable state and required a full demolition of the remaining bridges. At the same time, to ensure the smooth and safe demolition of the remaining bridges, the traffic and navigation channels on and under the Zijin Bridge were also closed off. 


\section{Collapse Process and Direct Reason Analysis}

Figure 5 illustrates the structure of Zijin Bridge. As shown in this figure, the structure of the bridge consists of five piers and two abutments where the dotted lines indicate the collapsed sections of the bridge. Figure 6 shows the real picture of the Zijin bridge before the collapse. Figure 7 shows the picture of the Zijin bridge after the collapse.

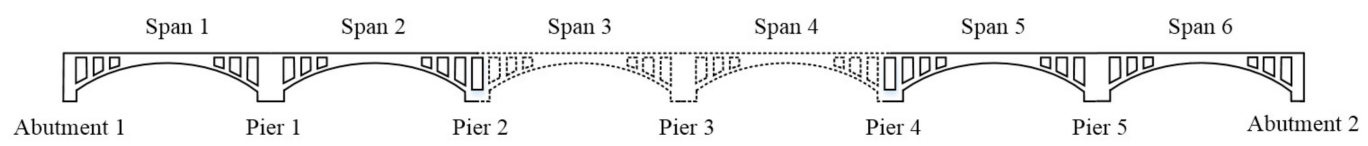

Figure 5. Zijin Bridge structure sketch.

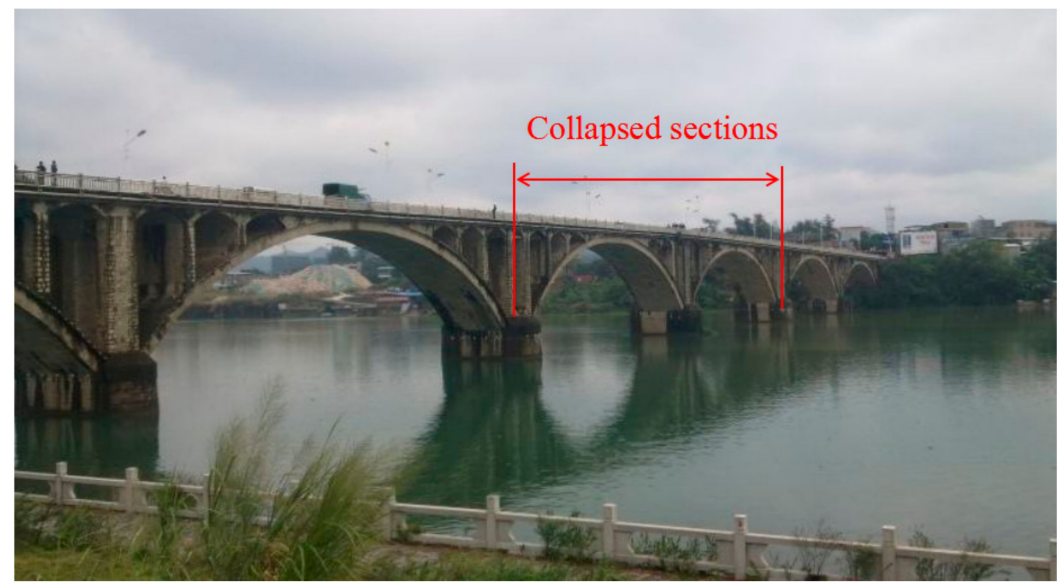

Figure 6. Zijin bridge before collapse [Picture source: http://bbs.076299.com/read-htm-tid-1773104fpage-207.html].

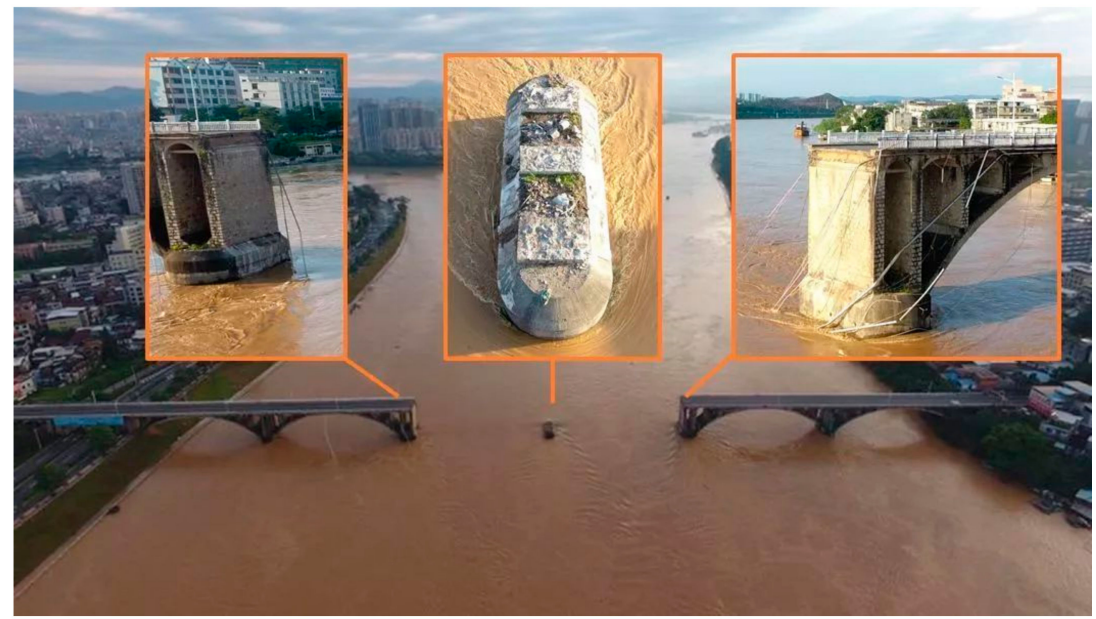

Figure 7. Broken column and bridge body on both sides of the column after collapse [Picture source: https://new.qq.com/omn/20190614/20190614A0E3YB.html].

Figure 8 illustrates the process of bridge collapse. According to the monitoring video and recording analysis by Peng [47], the details of the collapse process is presented below:

At 2:12:19 a.m., when the front vehicle was driving to the position of Pier 3, and the rear vehicle was driving to the middle of span 2, the first plastic hinge [49,50] appeared at the side of Pier 2 near span 3 then the deck near Pier 2 suddenly sank, the deck tilted, and the collapse began (see Figure 8a) [51].

At 2:12:20 a.m., the second plastic hinge appeared in span 3 near Pier 3, and then the span 3 structure became a non-statically indeterminate structure [52]. When the front vehicle entered span 4 , 
a new plastic hinge appeared in the middle of span 3 and the bridge deck of span 3 collapsed along with the rear vehicle (see Figure 8b).

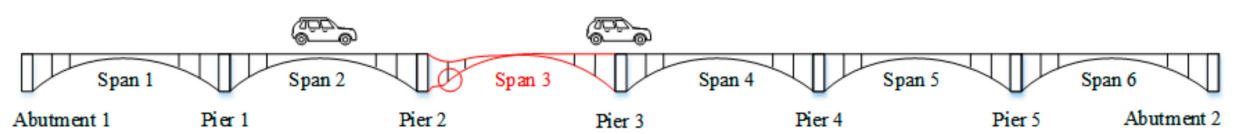

(a)

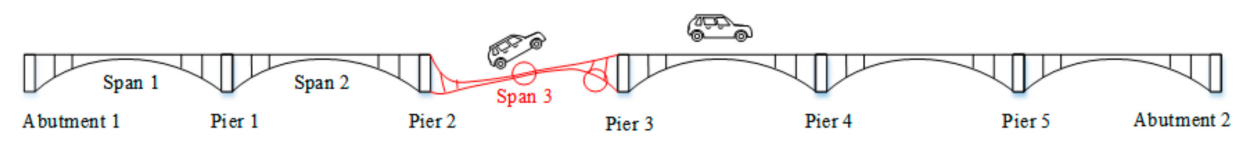

(b)
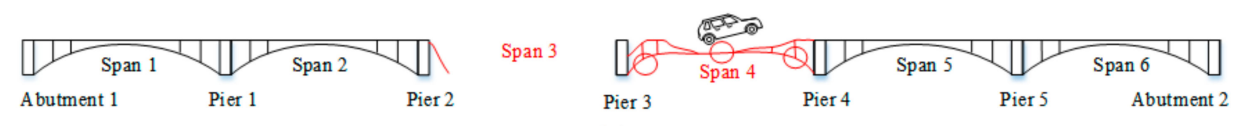

(c)

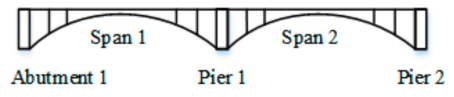

Span 3

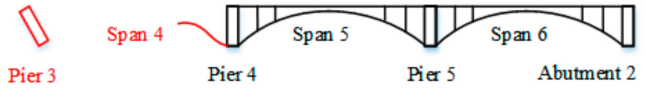

(d)

Figure 8. Sketch of the bridge collapse at (a) 2:12:19 a.m. (b) 2:12:20 a.m., (c) 2:12:22 a.m. and (d) 2:12:23 a.m. (the circle represents the position where plastic hinges occur).

At 2:12:22 a.m., after span 3 wholly collapsed, a plastic hinge appeared in the middle of span 4 . With the sinking of the middle span, new plastic hinges appeared on both sides of span 4 . Then span 4 collapsed, and the front car sank along with the bridge deck in the middle of span 4 (see Figure 8c).

At 2:12:23 a.m., the front car and span 4 fell into the water, the Pier 3 column fell in the direction of span 3 and eventually broke and fell into the water (see Figure 8d).

Emergency rescue was launched by the management and rescue departments of the local government immediately after the collapse. The two submerged vehicles were salvaged separately on 16 and 17 June. The Heyuan City Highway Bureau issued a bulletin on 17 July that the Zijin Bridge was in a highly dangerous and uncontrollable state and full demolition of the remaining bridge was required. Traffic and navigation channels on and under the Zijin Bridge were closed to ensure the smooth and safe demolition of the remaining bridge structure.

According to the monitoring video, it was determined that the trigger cause of the accident was an arch foot failing at Pier 2, which caused the collapse of the arch ring in span 3. The collapse of span 3 caused a chain reaction that resulted in the new plastic hinge of the arch ring. Finally, it formed a mechanism that caused the middle two spans to collapse and fall into the water. Fortunately, the second and the fourth piers were rigid, which resisted the unbalanced thrust caused by the collapse of the third and fourth spans, and the bridge did not collapse completely.

The impact of river water scouring on Zijin Bridge over the past 47 years cannot be neglected. The previous studies indicated that scouring, which often occurs at abutments, piers and other bridge substructures has a significant impact on bearing capacity [53,54]. It can be inferred from Figure 9, under the long-term scouring of flooding, the sediment around the upstream surface of Pier 3 foundation was taken away and the depth of the foundation of Pier 3 on upstream side was inadequate, resulting in the inclination and further weakening of the bearing capacity of Pier 3.

In addition, experts believe that the long-term illegal sand mining activity downstream of the bridge might also be related to the accident-long-term illegal sand extraction may empty the river sand downstream of the pier, leading to the displacement of the pier. In 2009, the Heyuan Evening News reported that in the Dongjiang River channel in the Yuancheng District, there were 10 illegal sand yards with more than 36,000 cubic meters of river sand stored from Dongjiang. When illegal sand mining was at its most serious, more than 20 sand dredgers operated on the river. 


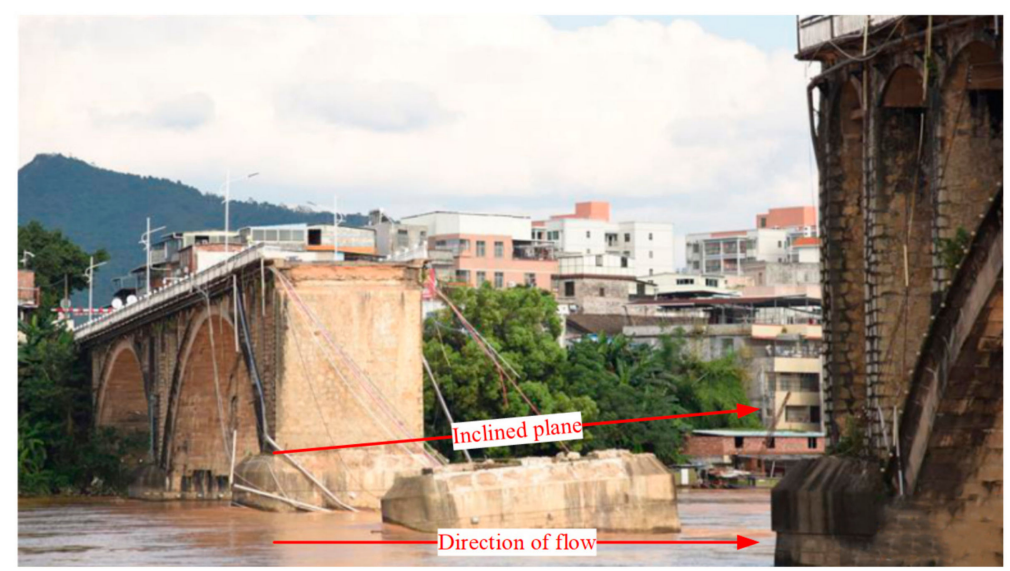

Figure 9. Inclination of the foundation of Pier 2.

\section{Analysis Methods}

The methodology for the management analysis of bridge failure includes fault tree analysis (FTA) and strategic environmental assessment (SEA). Figure 10 shows a schematic flow chart for bridge failure analysis used in this paper. First, a detailed analysis of the failure process was adapted to analyze the causes of failures [53]. For direct reason analysis, numerical simulation, such as a finite-element method (FEM), was performed to identify the trigger cause and quantitatively verify the bridge failure process [53]. Since this study pays more attention to the managerial reasons based on the technical analyzed results, the detailed technical analysis as reported by Peng [53] was used. Management cause as an indirect reason may be more significant than the technical reason, so FTA and SEA were used. Based on technical analysis, FTA was used to show the overall causes of the Zijin Bridge collapse and further classify the failure causes qualitatively. SEA was used to assess the management risks of bridge management and provide guidelines for bridge sustainability. SEA analysis was adopted based on six principles for SEA effectiveness to assess the risk probability scores in bridge sustainability. Furthermore, combined with FTA, management analysis using SEA proposed countermeasures and management guidelines for decision-making in development projects, which is pivotal for improving sustainability in terms of society, environment and economy.

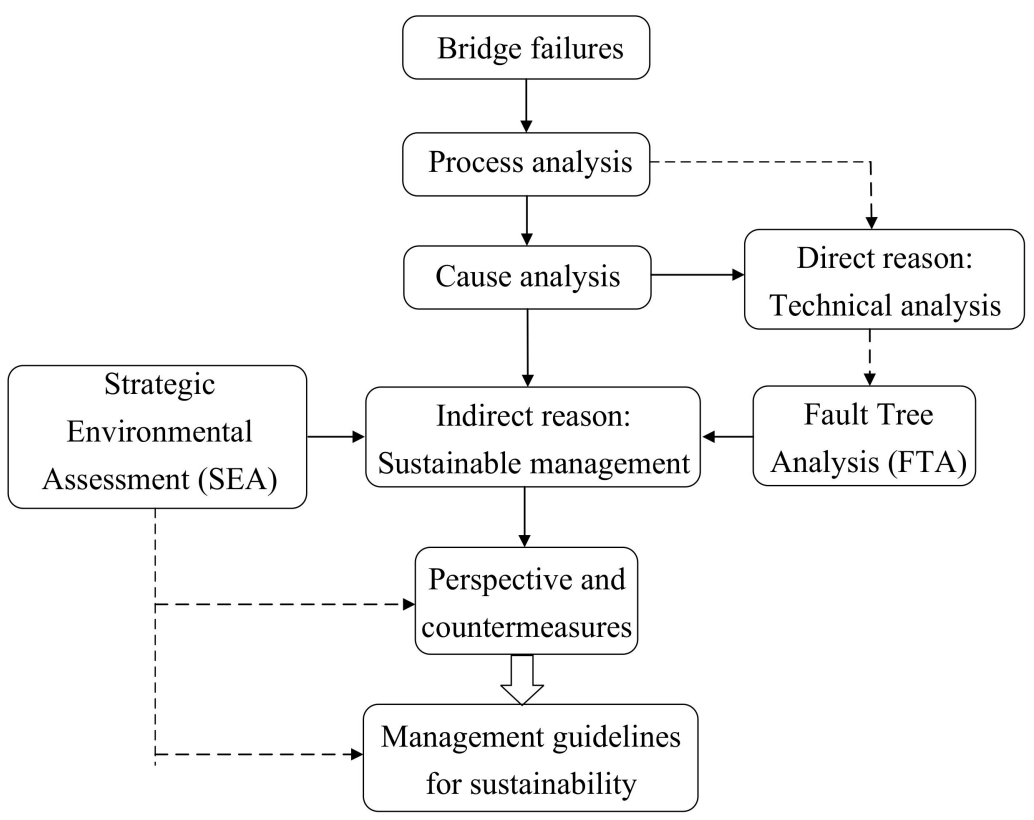

Figure 10. Bridge failure analysis process. 


\section{Fault Tree Analysis (FTA)}

FTA was used to reveal the collapse reasons of Zijin Bridge. Due to difficulties in conducting field tests to investigate the bridge's collapse and measured data collection, numerical analysis was performed. The numerical simulation method was performed to back-analyze the failure process and identify the failure causes [55,56]. Before FTA, FEM numerical analysis was conducted using Ansys 17.0 to simulate the finite element model (FEM) of collapsed sections (span 3 and span 4) of the Zijin Bridge. The detailed FEM simulation followed a similar method to that introduced by Peng $[53,54]$. To simulate the failure at the arch foot of span 3 near Pier 2, the stiffness of the material element at the arch foot was weakened to about one thousandth of the strength of other elements.

According to the first strength theory [53,54], the main failure factor of brittle materials such as concrete is that the maximum tensile stress exceeds the material limit. Therefore, in this paper, the first principal stress $S_{1}$ of the structure is analyzed, as shown in Figure 11. Comparing the simulated results with video analysis results presented in Figure 3, the location of the maximum first principal stress is the same as that of the plastic hinge in Figure 8. The deformation at the collapse time of span 3 and 4 is also similar to the actual situation. Therefore, it is proved that the trigger cause of the collapse of Zijin Bridge is the destruction of third spans of the arch foot near Pier 2.

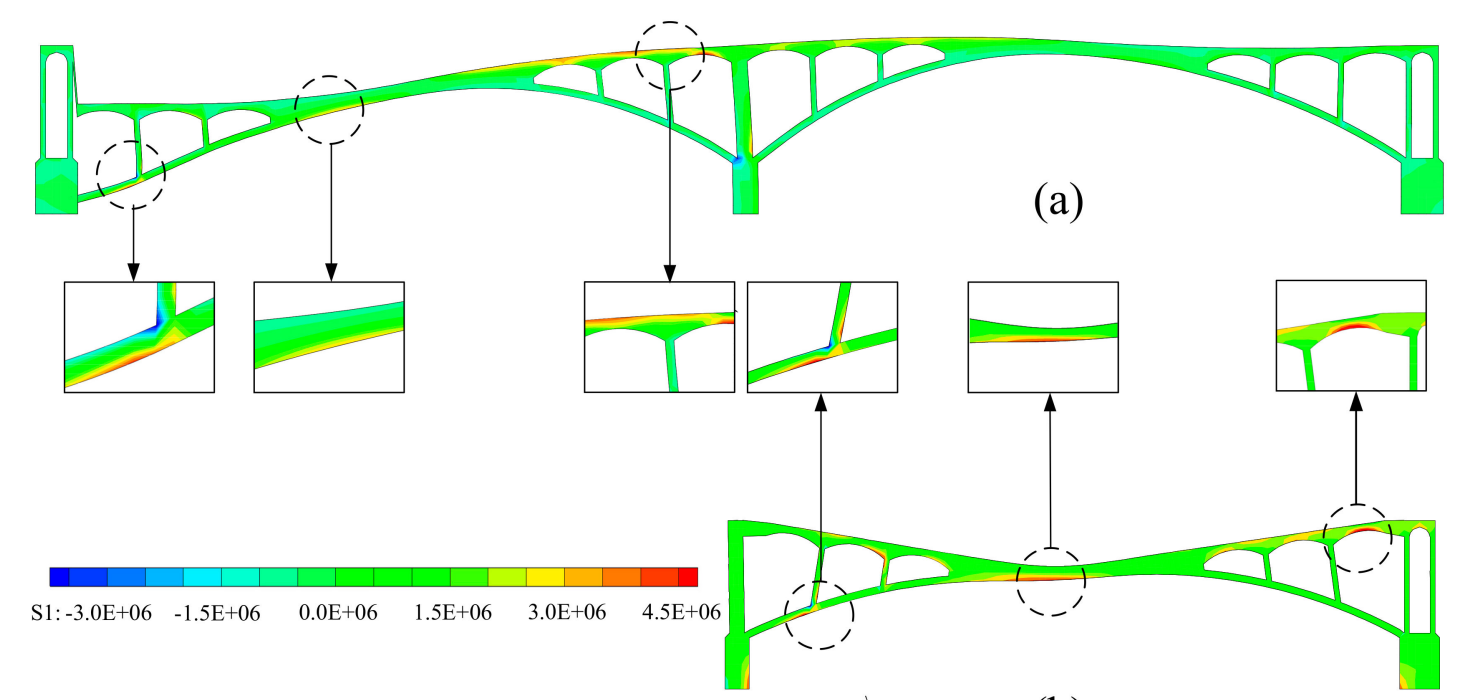

(b)

Figure 11. Maximum principal stress and deformation diagram of the bridge model when (a) span 3 begins to collapse (b) span 3 has collapsed completely.

Based on the FEM results and process analysis, an FTA diagram was simulated. The FTA structure is illustrated in Figure 12. According to the FTA structure, the top event is the collapse of Zijin Bridge. The basic events at the bottom consist of the causes of the collapse. The collapse of span 3 , span 4 and Pier 3 are intermediate events. All events are connected by "AND" and "OR" symbols logically. Arch foot failure directly resulted in the collapse of span 3 . With the demand of social development, the changing external circumstances such as the constant increasing of the traffic volume value and river flow value increased the traffic load and reduced the bearing capacity. Additionally, inadequate management measures including decision errors and lack of regular inspection had a long-term effect on the bridge structure. Hence, the collapse of span 3 and the setting of flexible Pier 3 caused the collapse of span 4. Due to aggravated river scouring and inadequate reinforcement measures, Pier 3 collapsed. It can be illustrated that the arch foot failure is a crucial technical factor leading to the whole collapse of span 3 and span 4. In addition to normal events for bridges like river scouring, setting of the flexible pier and ever-changing circumstance, inadequate management measures are potential comprehensive factors causing the collapse. Moreover, when the collapse happened, the bridge had 
been in service for nearly 50 years, and the load on the bridge deck was small, which confirms that the management of bridge engineering is worth further study.

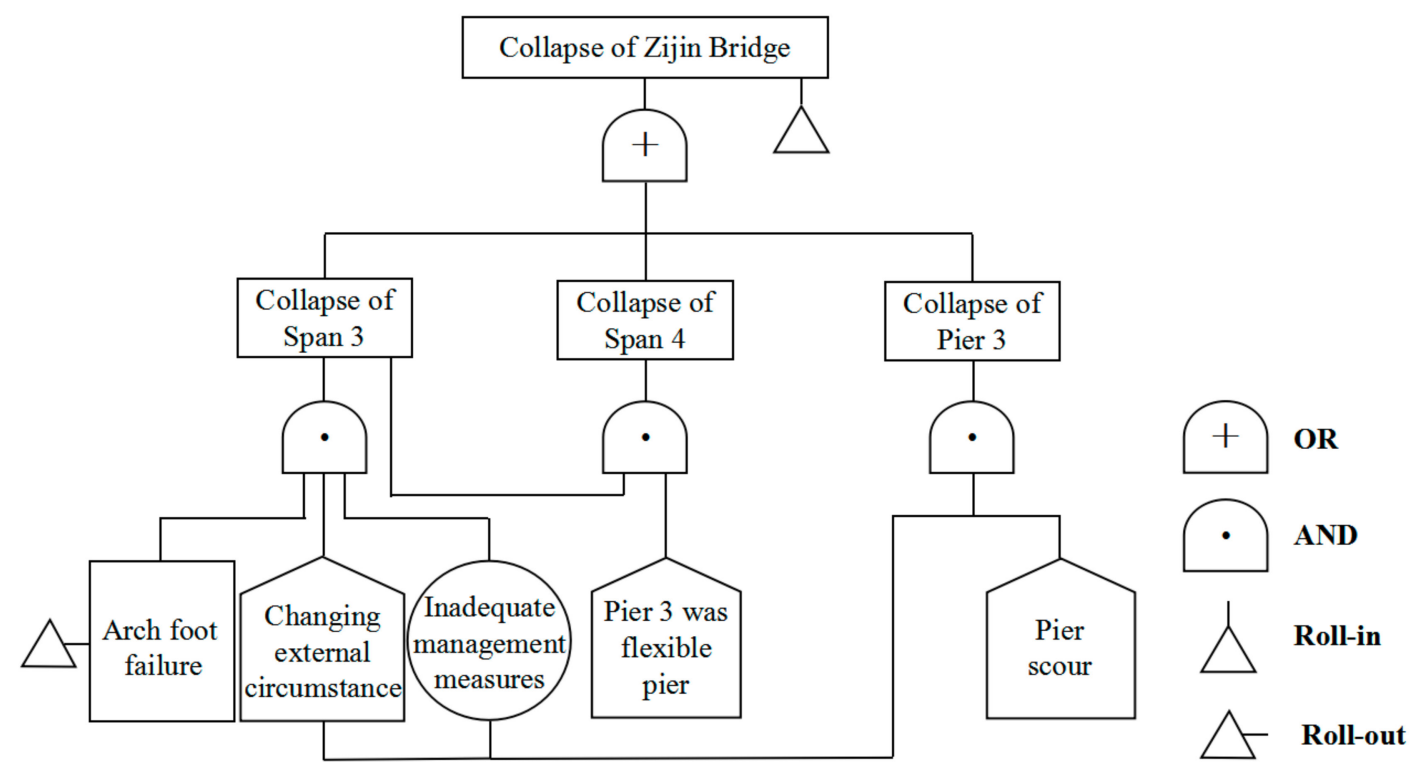

Figure 12. Main fault tree of Zijin Bridge collapse.

\section{SEA Analysis}

Since SEA is a good practice criteria for large-scale projects [45], in the following context, SEA analysis was adopted based on six principles $[57,58]$ in contrast to the management measures of urban bridges issued in order by the Ministry of Construction of China [59].

Figure 13 shows the main content diagram of the management measures for the inspection, maintenance and repair of Urban Bridges (Order No. 118, The Ministry of Construction, China). SEA assessment was conducted by comparing articles one by one between the established management measures by the government [59] and the field implementation. Table 1 shows the SEA evaluated results of Zijin Bridge based on regulations of the Ministry of Construction [59]. The score of SEA is given according to the following categorized management factors: (1) sustainability principles were taken into account in the bridge design phase, but the sustainability principles were been adjusted and improved during operation management and maintenance with the change of environment during bridge service; (2) insufficient monitoring of bridge structural stability during bridge service. The construction scope and operation (Article 14 and 15 of Order 118) were not well controlled; (3) despite the promulgation of relevant regulations on sand mining in rivers, the punishment for illegal sand excavation by regulatory authorities is insufficient and sand excavation has a continuous cumulative impact on the environment, which violates Article 25 of Order 118. The link between administrative law enforcement and criminal justice should be strengthened. (4) The impact of environmental integrity on decision making and the assessment of the environment is not considered accurately. During flood season, the storage capacity of the reservoir was not considered and the emergency inspection (Article 20 of Order 118) of flood discharge of reservoirs on downstream bridges was not implemented. The construction scope of reservoirs (infrastructures near the bridge (Article 14 of Order 118) was not well controlled; (5) a lack in effective management decision making and measures. The bridge had been put into use before the hidden danger of bridge was solved completely, which violates Article 23 of Order 118. Zijin Bridge underwent major maintenance in November 2015. However, the partial collapse accident occurred at Zijin Bridge in 2019. Bridge maintenance was carried out, but the expected results were not achieved. In addition, traffic restrictions of Zijin Bridge imposed in 2007 and abolished in 2008 had only been implemented for one year; (6) Negative social impacts are not taken into consideration. The traffic 
and navigation channels on and under the Zijin Bridge were closed off after the collapse, resulting in inconvenience and complications in transportation.

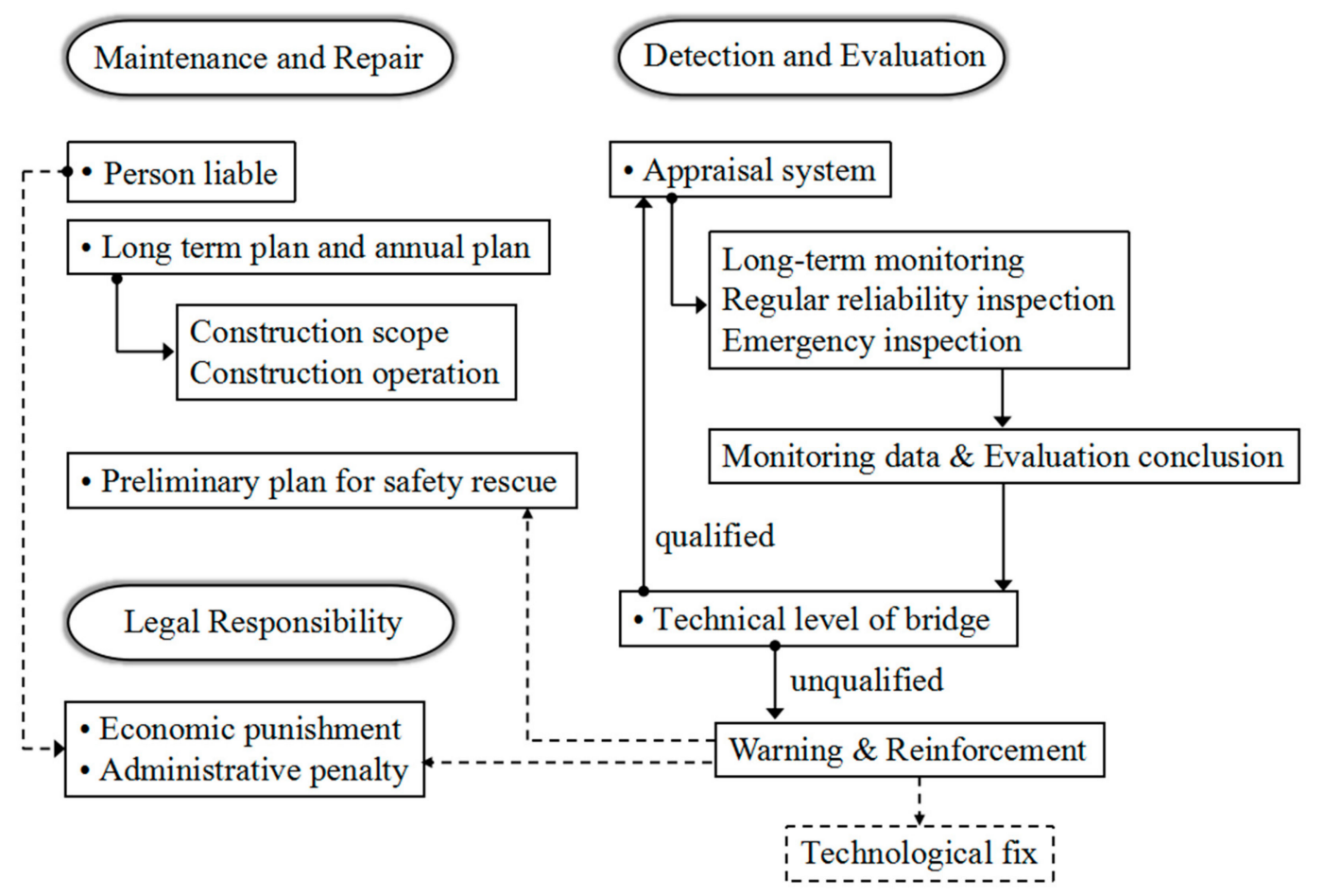

Figure 13. Main content block diagram of the management measures for the inspection, maintenance and repair of urban bridges (Order No. 118, The Ministry of Construction, China).

Table 1. Itemized evaluation of Zijin Bridge using strategic environmental assessment (SEA) principles.

\begin{tabular}{clc}
\hline SEA Principle & \multicolumn{1}{c}{ Project Management of Zijin Bridge } & Score out of 5 \\
\hline 1 & Yes: Sustainability principles were considered & 3 \\
\hline 2 & Not perfect: Professional monitoring mechanisms after 2008 & 2 \\
\hline 3 & $\begin{array}{l}\text { Not perfect: Powerful administrative law enforcement and criminal justice; } \\
\text { Proper emergency inspection }\end{array}$ & 2 \\
\hline 4 & $\begin{array}{l}\text { Not perfect: Consideration of environmental integrity and assessment of the } \\
\text { environmental bearing capacity }\end{array}$ & 1 \\
\hline 5 & Not perfect: Effective management decision-making and measures; & 2 \\
\hline Total score & Not perfect: Positive social impact & 11 \\
\hline
\end{tabular}

Note: If SEA principles are perfectly followed, a full score of 5 is awarded for each principle; the total score for the SEA principles is out of 30 .

According to the above categorized management factors, a score of only eleven (11) out of a total of 30 points was obtained. On the basis of SEA analysis, the risk of Zijin Bridge was far higher than the acceptance criteria.

\section{Discussion: Guideline of Sustainable Management}

To avoid similar infrastructure failures in the future, in view of the above causes in the bridge collapse case, both design countermeasures and management guidelines are proposed.

The design countermeasures can be further divided into static and dynamic retrofit solutions. As static retrofit solutions of bridges, specific materials like carbon fiber-reinforced concrete can be applied to the vulnerable parts of bridge arch feet, bridge columns, pier connections, etc. This helps to resist impact and scouring, which can prevent or reduce sudden accidents [38]. It can also improve the risk resistance under extreme conditions. Specifically, for arch bridges, the design of rigid 
piers is extremely important in multi-span continuous bridges, because it can effectively resist the unbalanced thrust caused by the collapse of one-sided arch spans and thereby prevent the continuous collapse [60-62]. As dynamic retrofit solutions of bridges, reasonable dynamic isolation approaches like inelastic hinges and other devices can prevent and reduce bridge failure caused by earthquakes. Multi-attribute utility theory (MAUT) can provide a general approach to evaluate the sustainability of bridges in terms of seismic retrofit optimization and aid the decision maker in making informed choices [44].

To improve the management of bridges and other infrastructures, considering social, environmental and economical sustainability, the following management guidelines for bridges and other infrastructures based on the implemented analysis are provided (see Figure 14):

Step I:

SEA Incorporation

Step II:

Intelligent risk

assessment system

Step III:

Correlative decisional management system

Step IV:

Efficient prevention
- Sustainability

- Environmental health

- Lond-term and stable policy

- Powerful and decisional supervision

- Effective countermeasures

- Sound rules and regulations

Total score $>24$

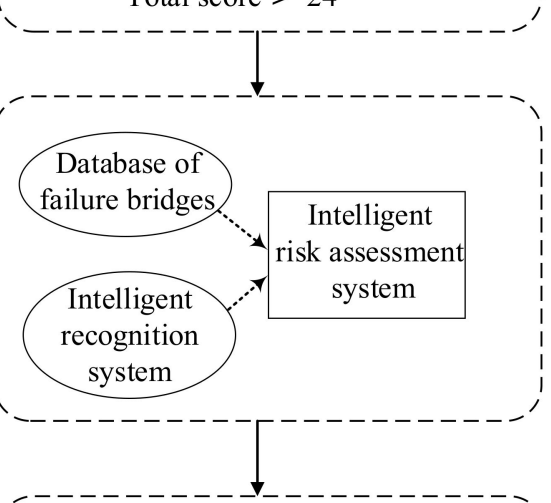

Sustainability: Three pillars

Design stage

Designer

Supervisor

Administrator

Engineer

Administrator

Construction stage-- Operational stage

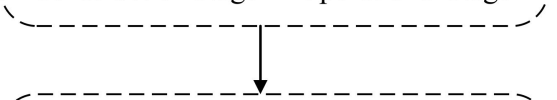

Daily management core:

Prevention

- Implemented monitoring program

- Clear procedure for periodic maintenance

- Detection of nonconformities

- Alarm system

...

Figure 14. Management guidelines for bridge and other infrastructures.

Step I Improve the management system with modern and adjusted SEA principles; SEA is recommended to be incorporated into comprehensive project management. According to the Environmental Protection Law of the People's Republic of China, the total score of the SEA should be higher than 24 [59]; 
Step II Establish and update an intelligent risk assessment system [63,64]. Today's risk assessment performed by inspectors is insufficient and inconsistent. Intelligence recognition systems that are applied to the unified database for failed bridges can assist in improving the accuracy and effectiveness of the risk assessment. Hence, knowledge-based expert systems (KBE) and artificial intelligence (AI) systems are the key technical procedures for the intelligence recognition systems, which can be used for accurate and reliable post-disaster condition assessments like crack and stress concentration identification [51].

Step III Adopt the correlative decisional management system. The adaptive management system consists of the designer in the design stage, the engineer in the construction stage, the administrator in the operational stage, and the supervisor during the whole period. Each level of management has corresponding responsibilities and should take the three pillars of sustainability into consideration. It is crucial to establish a correlative decisional and cooperation mechanism for the whole management.

Step IV Adopt efficient and diversified means of prevention, which are the essence of daily management. The monitoring and clear procedures for periodic maintenance are an important part of preventing failures. In addition, the detection of nonconformities and alarm systems play a major role in emergency situations, helping to establish a complete daily management system.

\section{Conclusions}

This paper investigated the managerial reasons for bridge collapse using FTA and failure-induced environmental impacts using SEA. Statistics on recent bridge failures in China were analyzed. Moreover, management guidelines were proposed based on SEA evaluation. The main conclusions are summarized as follows:

1. The statistical analysis on the bridge failures from 2009 to 2019 showed that about $70 \%$ of bridge failures were due to anthropic factors, which is a much larger proportion than those caused by natural factors (30\%). These safety accidents cause great losses of life and property, which expose the problems in bridge construction management hindering the sustainable development of society.

2. Zijin bridge failure was used as a case study to analyze the reasons relating to a lack of sustainable management. The FTA results show that the arch foot failure was the direct triggering cause of the Zijin bridge collapse. Moreover, a lack of real-time monitoring, risk assessment and other management issues were potential comprehensive factors causing the bridge collapse.

3. The SEA method was conducted to evaluate the management risk of Zijin Bridge. The low scores illustrated the high risk and negative impact on the community for this case. It is verified that SEA is an effective method for integrating sustainability principles related to societal, economic, cultural, human health and environmental factors in decision making relating to the development of bridge projects;

4. To improve the bridge sustainability, the following management guidelines on the basis of SEA were proposed: (i) a management system improved by SEA; (ii) an intelligent risk assessment system; (iii) perfecting the correlative decisional management system; (iv) efficient and diversified means of prevention.

Author Contributions: This paper represents a result of collaborative teamwork. K.E. and J.S.S. developed the concept; J.-S.T. draft the manuscript; Z.-F.W., J.S.S. and J.C. provided constructive suggestions and revised for the manuscript. The four authors contributed equally to this work. All authors have read and agreed to the published version of the manuscript.

Funding: The research work described herein was funded by the Research Funding of Shantou University for New Faculty Member (Grant No. NTF19024-2019), and also funded by the Innovative Research Funding of the Science and Technology Commission of Shanghai Municipality (Grant No. 18DZ1201102). These financial supports are gratefully acknowledged.

Conflicts of Interest: The authors declare no conflict of interest. 


\section{References}

1. Wu, H.-N.; Shen, S.-L.; Yang, J. Identification of tunnel settlement caused by land subsidence in soft deposit of Shanghai. J. Perform. Constr. Facil. 2017, 31, 04017092. [CrossRef]

2. Wu, H.-N.; Shen, S.-L.; Yang, J.; Zhou, A. Soil-tunnel interaction modelling for shield tunnels considering shearing dislocation in longitudinal joints. Tunn. Undergr. Space Technol. 2018, 78, 168-177. [CrossRef]

3. Lyu, H.M.; Sun, W.J.; Shen, S.L.; Arulrajah, A. Flood risk assessment in metro systems of mega-cities using a GIS-based modeling approach. Sci. Total Environ. 2018, 626, 1012-1025. [CrossRef] [PubMed]

4. Wu, Y.X.; Shen, S.L.; Lyu, H.M.; Zhou, A.N. Analyses of leakage effect of waterproof curtain during excavation dewatering. J. Hydrol. 2020, 583, 124582. [CrossRef]

5. Lyu, H.M.; Sun, W.J.; Shen, S.L.; Zhou, A.N. Risk assessment using a new consulting process in fuzzy AHP. J. Constr. Eng. Manag. 2020, 146, 04019112. [CrossRef]

6. Ruiz, A.; Guevara, J. Sustainable Decision-Making in Road Development: Analysis of Road Preservation Policies. Sustainability 2020, 12, 872. [CrossRef]

7. Elbaz, K.; Shen, S.L.; Zhou, A.N.; Yuan, D.J.; Xu, Y.S. Optimization of EPB shield performance with adaptive neuro-fuzzy inference system and genetic algorithm. Appl. Sci. 2019, 9, 780. [CrossRef]

8. Shen, S.-L.; Wu, H.-N.; Cui, Y.-J.; Yin, Z.-Y. Long-term settlement behavior of metro tunnels in the soft deposits of Shanghai. Tunn. Undergr. Space Technol. 2014, 40, 309-323. [CrossRef]

9. De Luca, S.; Di Pace, R.; Memoli, S.; Pariota, L. Sustainable Traffic Management in an Urban Area: An Integrated Framework for Real-Time Traffic Control and Route Guidance Design. Sustainability 2020, 12, 726. [CrossRef]

10. He, X.C.; Yang, T.L.; Shen, S.L.; Xu, Y.S.; Arulrajah, A. Land subsidence control zone and policy for the environmental protection of Shanghai. Int. J. Environ. Res. Public Health 2019, 16, 2729. [CrossRef]

11. Lyu, H.M.; Cheng, W.C.; Shen, J.; Arulrajah, A. Investigation of Collapsed Building Incidents on Soft Marine Deposit: Both from Social and Technical Perspectives. Land 2018, 7, 20. [CrossRef]

12. Xu, H.T.; Guo, G.Z.; Pu, H.L.; Yuan, M. Causes and Lessons of Bridge Accidents in China in Recent Years. China Saf. Sci. J. 2007, 17, 90-95+176. [CrossRef]

13. Zhou, X.H.; Shen, S.L.; Xu, Y.S.; Zhou, A.N. Analysis of Production Safety in the Construction Industry of China in 2018. Sustainability 2019, 11, 4537. [CrossRef]

14. Wu, Y.X.; Lyu, H.M.; Han, J.; Shen, S.L. Dewatering-induced building settlement around a deep excavation in soft deposit in Tianjin, China. J. Geotech. Geoenvironmental Eng. 2019, 145, 05019003. [CrossRef]

15. Lyu, H.M.; Shen, S.L.; Zhou, A.N.; Zhou, W.H. Flood risk assessment of metro systems in a subsiding environment using the interval FAHP-FCA approach. Sustain. Cities Soc. 2019, 50, 101682. [CrossRef]

16. Yan, T.; Shen, S.L.; Zhou, A.N.; Chen, J. A Brief Report of Pingdi Landslide (23 July 2019) in Guizhou Province, China. Geosciences 2019, 9, 368. [CrossRef]

17. Lyu, H.M.; Shen, S.L.; Yang, J.; Yin, Z.Y. Inundation analysis of metro systems with the storm water management model incorporated into a geographical information system: A case study in Shanghai. Hydrol. Earth Syst. Sci. 2019, 23, 4293-4307. [CrossRef]

18. Chai, J.; Shen, S.; Ding, W.; Zhu, H.; Carter, J. Numerical investigation of the failure of a building in Shanghai, China. Comput. Geotech. 2014, 55, 482-493. [CrossRef]

19. Atangana Njock, P.G.; Shen, S.L.; Zhou, A.N.; Lyu, H.M. Evaluation of soil liquefaction using AI technology incorporating a coupled ENN/t-SNE model. Soil Dyn. Earthq. Eng. 2020, 130, 105988. [CrossRef]

20. Lyu, H.M.; Shen, S.L.; Yang, J.; Zhou, A.N. Risk assessment of earthquake-triggered geohazards surrounding Wenchuan, China. Nat. Hazards Rev. 2019. [CrossRef]

21. Zhang, N.; Shen, S.-L.; Zhou, A.-N.; Chen, J. A brief report on the March 21, 2019 explosions at a chemical factory in Xiangshui, China. Process Saf. Prog. 2019, 38, e12060. [CrossRef]

22. Zhang, N.; Shen, J.S.; Lin, C.; Arulrajah, A.; Chai, J.-C. Investigation of a large ground collapse and countermeasures during mountain tunnelling in Hangzhou: A case study. Bull. Eng. Geol. Environ. 2019, 78, 991-1003. [CrossRef]

23. Zhang, N.; Shen, S.L.; Zhou, A.N.; Xu, Y.S. Investigation on performance of neural network using quadratic relative error cost function. IEEE Access 2019, 7, 106642-106652. [CrossRef]

24. Wang, X.W.; Yang, T.L.; Xu, Y.S.; Shen, S.L. Evaluation of optimized depth of waterproof curtain to mitigate negative impacts during dewatering. J. Hydrol. 2019, 577, 123969. [CrossRef] 
25. Lyu, H.M.; Shen, S.L.; Zhou, A.N.; Yang, J. Risk assessment of mega-city infrastructures related to land subsidence using improved trapezoidal FAHP. Sci. Total Environ. 2019, 135310. [CrossRef]

26. Xu, Y.S.; Shen, S.L.; Lai, Y.; Zhou, A.N. Design of Sponge City: Lessons learnt from an ancient drainage system in Ganzhou, China. J. Hydrol. 2018, 563, 900-908. [CrossRef]

27. Elbaz, K.; Shen, S.L.; Arulrajah, A.; Horpibulsuk, S. Geohazards induced by anthropic activities of geoconstruction: A review of recent failure cases. Arab. J. Geosci. 2016, 9. [CrossRef]

28. Lyu, H.M.; Wang, G.F.; Cheng, W.C.; Shen, S.L. Tornado hazards on June 23rd in Jiangsu Province, China: Preliminary investigation and analysis. Nat. Hazards 2017, 85, 597-604. [CrossRef]

29. Hersi, M.I. Analysis of bridge failures in the United States (2000-2008). Master's Thesis, Ohio State University, Columbus, OH, USA, 2009.

30. Zhao, X.-H.; Cheng, W.-C.; Shen, J.S.; Arulrajah, A. Platform collapse incident of a power plant in Jiangxi, China. Nat. Hazards 2017, 87, 1259-1265. [CrossRef]

31. Xu, Y.-S.; Yan, X.-X.; Shen, S.-L.; Zhou, A.-N. Experimental investigation on the blocking of groundwater seepage from a waterproof curtain during pumped dewatering in an excavation. Hydrogeol. J. 2019, 27, 2659-2672. [CrossRef]

32. Yu, C.; Zhou, A.; Chen, J.; Arulrajah, A.; Horpibulsuk, S. Analysis of a tunnel failure caused by leakage of the shield tail seal system. Undergr. Space 2019. [CrossRef]

33. Meng, W.L.; Shen, S.L.; Zhou, A.N. Investigation on fatal accidents in Chinese construction industry between 2004 and 2016. Nat. Hazards 2018. [CrossRef]

34. Dong, Y.; Frangopol, D.M.; Sabatino, S. Optimizing bridge network retrofit planning based on cost-benefit evaluation and multi-attribute utility associated with sustainability. Earthq. Spectra 2015, 31, 2255-2280. [CrossRef]

35. Blockley, D.I.; Henderson, J.R. Structural failures and the growth of engineering knowledge. Proc. Inst. Civ. Eng. 1980, 68, 719-728. [CrossRef]

36. Xu, F.Y.; Zhang, M.J.; Wang, L.; Zhang, J.R. Recent highway bridge collapses in China: Review and discussion. J. Perform. Constr. Facil. 2016, 30, 04016030. [CrossRef]

37. Cook, W. Bridge failure rates, consequences, and predictive trends. Ph.D. Thesis, Utah State University, Logan, UT, USA, 2014.

38. Wardhana, K.; Hadipriono, F.C. Analysis of recent bridge failures in the United States. J. Perform. Constr. Facil. 2003, 17, 144-150. [CrossRef]

39. Imam, B.M.; Chryssanthopoulos, M.K. Causes and consequences of metallic bridge failures. Struct. Eng. Int. 2012, 22, 93-98. [CrossRef]

40. Gonen, H.; Dogan, M.; Karacasu, M.; Ozbasaran, H.; Gokdemir, H. Structural failures in refrofit historical murat masonry arch bridge. Eng. Fail. Anal. 2013, 35, 334-342. [CrossRef]

41. Dong, Y.H. Research on bridge maintenance management system. Master's Thesis, Chang'an University, Xi'an, China, 2014. (In Chinese)

42. Rokneddin, K.; Ghosh, J.; Dueñas-Osorio, L.; Padgett, J.E. Seismic reliability assessment of aging highway bridge networks with field instrumentation data and correlated failures, II: Application. Earthq. Spectra 2014, 30, 819-843. [CrossRef]

43. Bridle, R.J.; Sims, F. The effect of bridge failures on UK technical policy and practice. Proc. Inst. Civ. Eng. Eng. Hist. Herit. 2009, 162, 39-49. [CrossRef]

44. Tapia, C.; Padgett, J.E. Multi-objective optimization of bridge retrofit and post-event repair selection to enhance sustainability. Struct. Infrastruct. Eng. 2016, 12, 93-107. [CrossRef]

45. Markus, E.; Emmelin, L. Applying good EIA practice criteria to SEA: The Öresund Bridge as a case. In Proceedings of the 5th Nordic Environmental Assessment Conference, Reykjavik, Iceland, 25-26 August 2003.

46. Bao, C.K.; Lu, Y.S.; Shang, J.C. Framework and operational procedure for implementing strategic environmental assessment in china. Environ. Impact Assess. Rev. 2004, 24, 27-46. [CrossRef]

47. Liu, M.M. Bridge Accident Analysis. Master's Thesis, Southwest Jiaotong University, Chengdu, China, 2013. (In Chinese)

48. Xing, J.X. The Whole Life Risk Assessment of Bridge Engineering. Master's Thesis, Taiyuan University of Science and Technology, Taiyuan, China, 2015. (In Chinese) 
49. Audenaert, A.; Fanning, P.; Sobczak, L.; Peremans, H. 2-D analysis of arch bridges using an elasto-plastic material model. Eng. Struct. 2008, 30, 845-855. [CrossRef]

50. Kim, S.E.; Choi, S.H.; Ma, S.S. Performance based design of steel arch bridges using practical inelastic nonlinear analysis. J. Constr. Steel Res. 2003, 59, 91-108. [CrossRef]

51. Bocchini, P.; Frangopol, D.M.; Ummenhofer, T.; Zinke, T. Resilience and sustainability of civil infrastructure: Toward a unified approach. J. Infrastruct. Syst. 2013, 20, 04014004. [CrossRef]

52. Wu, X.; Gu, D. Local stress analysis of arch foot for trough girder and arch composite bridge. Appl. Mech. Mater. 2014, 638, 961-964. [CrossRef]

53. Peng, W.B. Collapse Analysis of Dongjiang Bridge in Heyuan, Guangdong Province. J. China Highw. 2019. Available online: https://dwz.cn/xmpCHuBW (accessed on 15 June 2019). (In Chinese)

54. Zhai, W.; Xia, H.; Cai, C.; Gao, M.; Li, X.; Guo, X.; Wang, K. High-speed train-track-bridge dynamic interactions-Part I: Theoretical model and numerical simulation. Int. J. Rail Transp. 2013, 1, 3-24. [CrossRef]

55. Deng, L.; Wang, W.; Yu, Y. State-of-the-art review on the causes and mechanisms of bridge collapse. J. Perform. Constr. Facil. 2015, 04015005. [CrossRef]

56. Johnson, P.A. Fault tree analysis of bridge failure due to scour and channel instability. J. Infrastruct. Syst. 1999, 5, 35-41. [CrossRef]

57. Retief, F.A. performance evaluation of strategic environmental assessment (SEA) processes within the south African context. Environ. Impact Assess. Rev. 2007, 27, 84-100. [CrossRef]

58. Wu, Y.X.; Shen, J.S.; Cheng, W.C.; Hino, T. Semi-analytical solution to pumping test data with barrier, wellbore storage, and partial penetration effects. Eng. Geol. 2017, 226, 44-51. [CrossRef]

59. Ministry of Ministry of Construction of the People's Republic of China (MMCPRC). Management Measures for Inspection, Maintenance and Repair of Urban Bridges. Available online: http://www.gd.gov.cn/zwgk/ zcfgk/content/post_2531698.html (accessed on 20 December 2019). (In Chinese)

60. Vulnerability and failure analysis of hybrid cable-stayed suspension bridges subjected to damage mechanisms. Eng. Fail. Anal. 2014, 45, 470-495. [CrossRef]

61. A numerical study on the structural integrity of self-anchored cable-stayed suspension bridges. Frat. Integrità Strutt. 2016, 10, 359-376. [CrossRef]

62. Dynamic analysis of cable-stayed bridges affected by accidental failure mechanisms under moving loads. Math. Probl. Eng. 2013, 2013, 302706. [CrossRef]

63. Shang, H.; Anumba, C.J.; Bouchlaghem, D.M.; Miles, J.C.; Cen, M.; Taylor, M. An intelligent risk assessment system for distributed construction teams. Eng. Constr. Archit. Manag. 2005. [CrossRef]

64. Shang, H.; Anumba, C.J.; Bouchlaghem, D.M. An Intelligent Risk Assessment System for AEC. In Proceedings of the 2006 10th International Conference on Computer Supported Cooperative Work in Design, Nanjing, China, 3-5 May 2006; pp. 1-6. [CrossRef] 